\title{
Structure of Motivation for Training in Engineering Specialties
}

\author{
Grigor Grigorov \\ Vasil Levski National Military University, Bulgaria \\ Ilyan Lilov \\ Vasil Levski National Military University, Bulgaria
}

\begin{abstract}
This article researches the structure of motivation for training in engineering specialties as well as the satisfaction from it. It analyses the main factors that form students' motivation for training and the interrelationships between them. A comparative analysis of the state of the motivational structure is carried out of the opinions of both lecturers and students in engineering specialties, taking into account the similarities and differences between them. The article identifies the specific factors that form the motivation for the students in the aforementioned specialties, the problems in their training, and gives guidelines for their overcoming in order to improve the quality of training. The results of the research would contribute to raising the interest in training in engineering specialties, attracting and retaining motivated learners, and meeting the growing shortage of engineers on the labour market.
\end{abstract}

Keywords: motivation, training, engineering specialty

JEL classification: |21

\section{Introduction}

Being a professional engineer was extremely prestigious in the $60 \mathrm{~s}$ and 70 s of the last century. Then came the time of economists, financiers and lawyers. Nowadays, however, the prestige of the title Eng. next to your name is reviving again, perhaps mostly due to the IT industry (Cherkezova, 2014).

In recent years, there has been a growing need for professional engineers, at the expense of economists, lawyers, and managers. More and more employers claim that there is a shortage of technical specialists in our labour market and insist on state scholarships for engineers and technologists. Career development experts also warn that in the coming years the demand for all professional engineers will be increasing. The entrepreneur and founder of Walltopia, a climbing wall company, Ivaylo Penchev stated during the first specialised career show 'I, the engineer', "The world needs engineers. And be terribly proud of yourself if you have chosen this path of professional development because everything we use today has been invented by engineers. They are also behind almost all major companies" (Cherkezova, 2014).

The training in engineering specialties is carried out in the higher education system. This process is difficult and requires that learners are highly motivated to reach the ultimate goal - an engineering diploma. Attracting and retaining motivated learners as well as maintaining their active, committed attitude to the training process cannot be taken for granted, which makes it a top priority for universities as it is a prerequisite for providing highly qualified staff on the labour market. 
In recent years there has been a decline in student motivation in the training process. This necessitates the study of the structure of motivation for training in engineering specialties and the development of new models for attracting and retaining motivated students.

The purpose of this study is to establish the structure of the motivation for training in engineering specialties, the factors that compose it, as well as to establish the interrelation between them.

The working hypothesis in the study is that the dominating factors in the motivation structure when choosing an engineering specialty are both the factors related to external motivation (hygiene factors under F. Herzberg), which include training conditions, pay and security of future work, and the internal factors (satisfaction factors or motivators under F. Herzberg), which relate to progress, achievements in learning and the growth of the personality. In the training process, it is the internal factors that completely build up the motivational structure.

The term 'motivation' comes from Latin and means 'to move', 'stir' (Penchev, 2016). In the dictionary of foreign words in Bulgarian, the interpretation of 'motivation' is referred to as "a set of motives that determine an activity or action", and 'motive' should be understood as "urge, occasion, reason for an action" (Burov et al., 1995). Motivation is therefore the reason, the incentive, and the force that causes people to act in a certain way in order to achieve their goals. The motive, on its part, is a perceived incitement, leading to an action which is to satisfy an individual's need. Training is performed to meet the need for certain new knowledge, but what actually constitutes the motivational structure of the students in engineering specialties is the subject of this study.

The analysis of existing literature shows that motivation has a complex structure, it is inherent only to the individual or person and is characterised by a high degree of consciousness (Ivanov, 2005). For these reasons, it has been considered by many authors, such as Frederick Taylor, Elton Mayo, William Ouchi, Abraham Maslow, Frederick Herzberg, Vroom, McClelland, Skinner, Murray, etc. (Pencheva, 2007). In their works, they developed various motivational theories, which L. Mullins subsequently structured into two main groups. In the first group, he included what he called "content theories of motivation", and in the second, "process theories of motivation" (Mullins, 2013).

The first group includes Maslow's theory of the hierarchical model of human needs, Herzberg's two-factor theory, McClelland's theory, as well as Alderfer's and Murray's. The authors of this group view motivation in terms of its content characteristics, assuming that it can be linked to the mechanism of action of human needs. The question "What stimulates a behaviour?" is at their core. Thus, for example, Herzberg accepted and developed Maslow's theory of the hierarchy of human needs. He, however, divided the factors influencing the behaviour of the individual into two groups - external (hygiene) and internal (motivators). The external ones correspond to the lower levels of Maslow's hierarchy, and their lack affects initially the choice of a specialty because they are obvious in the university environment. The internal ones are related to the training in the particular specialty and lead to an increase in the motivation and satisfaction from the training itself.

The second group of process theories includes Vroom, Porter and Lawler's expectancy theories of motivation, Adams' theory of justice, Heider and Kelley's attribution theory, and Locke's goal-setting theory. These theories relate to their authors' understanding about the essence of motivation as a process. The emphasis in them is on the psychological processes involved in the formation of motivation. They explain why people choose a certain behaviour to meet specific needs. In the 
context of training, lecturers need to provoke learners' need to acquire new knowledge.

The motivation for training includes various motives that positively influence the training process and provoke learners' aspirations to learn the material and to overcome difficulties and tensions through the pursuit of continuous personal selfimprovement.

Motivation for training is also a subject of research for many Bulgarian authors, such as Stoyanova D., Kotseva T., Baltadzhieva Y., Mineva K., etc., who appreciate the level of academic motivation. There are authors such as Varadinova $Y$. Varadinova (2015), who offers in one of her articles a methodology for conducting surveys to assess the quality of training, which also reflects the level of motivation for training.

\section{Methodology for conducting the research}

The study of the structure of motivation for training in engineering specialties is based on a methodology developed specifically for the needs of this research and based on data collection through an online survey.

The object of the survey are two main target groups (categories) - students and lecturers in engineering specialties, with the following scope:

- students in engineering specialties - 68 people;

- lecturers in engineering specialties - 19 people.

To achieve the objectives of the survey, two types of questionnaires were developed, different for each category. They include two main parts: first part passport, and second part - questions, structured in groups to reflect the opinion of the interviewed persons.

The passport includes general information about the respondents such as:

- about the students - gender, age, training course, status and date;

- about the lecturers - gender, age, academic rank, educational and scientific degree and date.

In the second part there are structured questions which the respondents should answer, and the possibility of responding is in the form of a Likert scale, i.e. it is formulated as an evaluation with which the respondent can agree (or disagree) to varying degrees.

The scale consists of five degrees: 1 - very low; 2 - low; 3 - medium; 4 - high; 5 very high.

\section{Results}

The analysis of the results of the conducted survey was prepared by separate questions or groups of questions from the questionnaire, considering the opinion of all the inquired categories.

Questions № 1 and 2 of the student questionnaire refer to the choice of an engineering specialty and are worded as follows:

Question № 1: "To what extent do you consider the choice of a specialty was personally yours?"

Question № 2: "To what extent do you consider your choice of specialty was influenced by the opinion of people who were studying or had graduated an engineering specialty?"

The results of question № 1 (presented in Figure 1) and question № 2 indicate that the majority of respondents, over $75 \%$, state that the choice of an engineering 
specialty was theirs, and only about $20 \%$ of them declare that it was influenced by people who were studying or had graduated from such a specialty.

Figure 1

Answer to Question № 1 (Students)

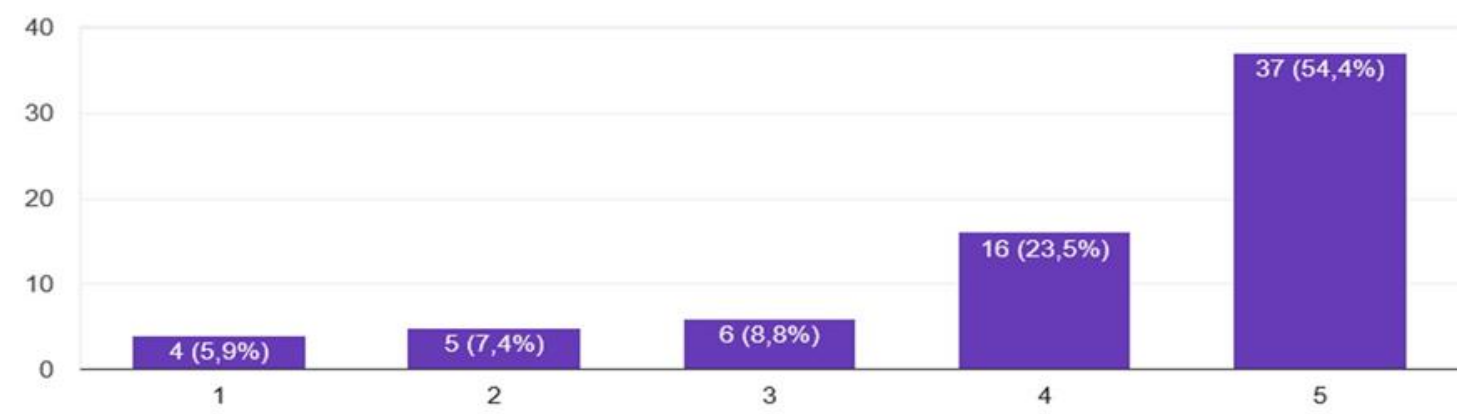

Source: Authors' illustration

Question № 3 of the students' questionnaire is identical to question № 1 of the lecturers' questionnaire and is related to the factors motivating the choice of an engineering specialty.

The analysis of the results on the questions leads to the idea that for the students the most important factors are the realisation on the labour market and better opportunities for further training. An important role is also played by the remuneration and location of their future occupation. Less important factors are the amount of tuition fees, the affinity for science, and the location of the university.

For the lecturers, the most important factors are the remuneration, their realisation on the labour market and the location of their future occupation. The analysis of these results shows that both students and lecturers find that realisation is the leading factor in the choice of an engineering specialty.

Questions № 9 and № 10 of the students' questionnaire and question № 6 of the lecturers' questionnaire reflect the views of the two categories of respondents on motivation for training.

The analysis of the answers to these questions shows that at the beginning of the training, over $70 \%$ of the students have a high or very high motivation, while in the course of their training the students who have such motivation are $45 \%$. This makes us think that something demotivates about $1 / 4$ of the students, and that is probably the difficulty in studying engineering disciplines. The lecturers' opinion on student motivation is different from that of the students. About half of the lecturers surveyed stated that students' motivation was low. The differences in the viewpoints of the surveyed categories indicate that students want to be trained, but their lecturers do not think their motivation is high enough for that.

Question № 14 of the students' questionnaire is identical to question № 10 of the lecturers' questionnaire and is related to factors influencing motivation in the training process. The questions are formulated as follows: "To what extent do you think the following factors influence the motivation for training?"

The questions are structured in thirteen sub-items containing various factors influencing motivation for training. In this way, respondents are given the opportunity to indicate what they think is the degree of importance of each of the factors mentioned. 
The results of question № 14 (presented in Figure 2) and question № 10 indicate that the main factors influencing the motivation for training, according to the students are: the way of teaching, the combination of theoretical and practical classes, the relation between the results of the training and finding a job, the opportunity for practice or internship programmes in private engineering enterprises, the content of curricula and syllabi, research opportunities and experiments. According to the lecturers, the most important factors are: the condition of the university facilities, the opportunity for a practicum or internship programmes in private engineering enterprises, the way of teaching, the combination of theoretical and practical classes, the content of curricula and syllabi, and the use of interactive learning methods. The analysis of the results on the question shows that most of the key factors are mentioned both by the students and by the lecturers. Of these factors, the way of teaching, the practical orientation of the training and the content of the curricula and syllabi stand out. This shows that for both categories surveyed the most important is the learning content and how it will be presented so that it is learnt well.

Figure 2

Answer to Question № 14 (Students)

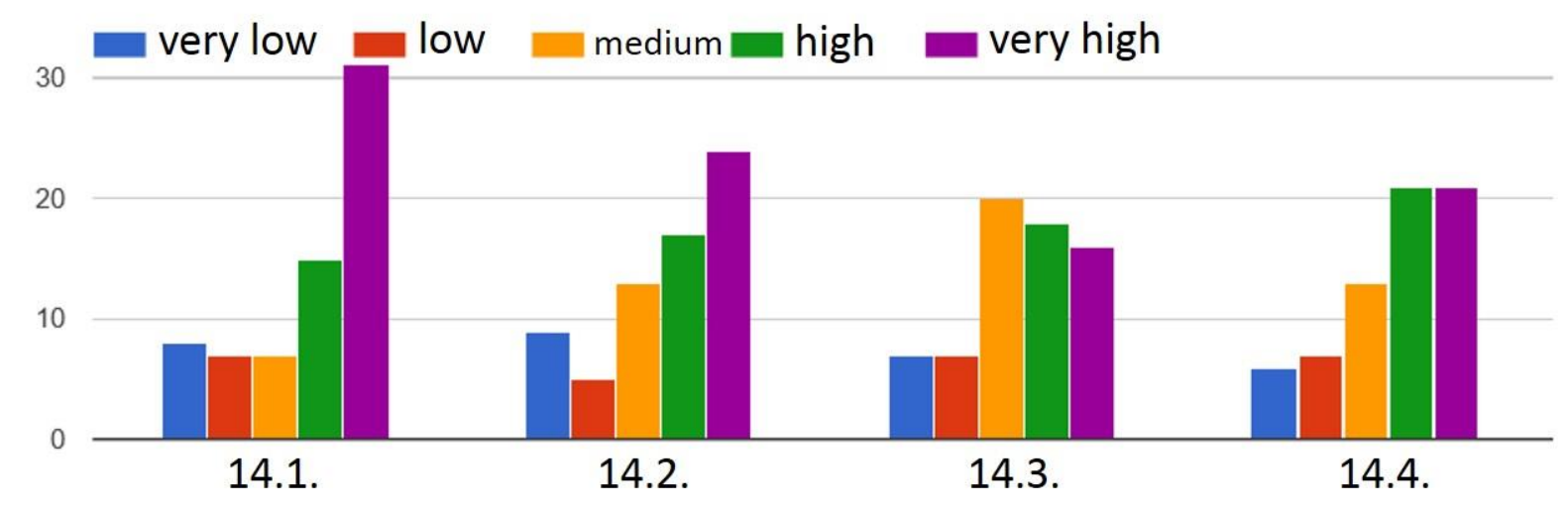

Source: Authors' illustration

Question № 15 of the students' questionnaire is identical to question № 11 of the lecturers' questionnaire and is worded as follows: "To what extent do you think that student-teacher feedback influences your motivation for training?"

Both students and lecturers unanimously share the opinion that regular feedback is of the utmost importance.

Questions № 16, 17 and 20 of the students' questionnaire and questions № 12 and 15 of the lecturers' questionnaire refer to the level of practical training of students and the relationship between the training received and finding a job. 
Figure 3

Answer to Question № 17 (Students)
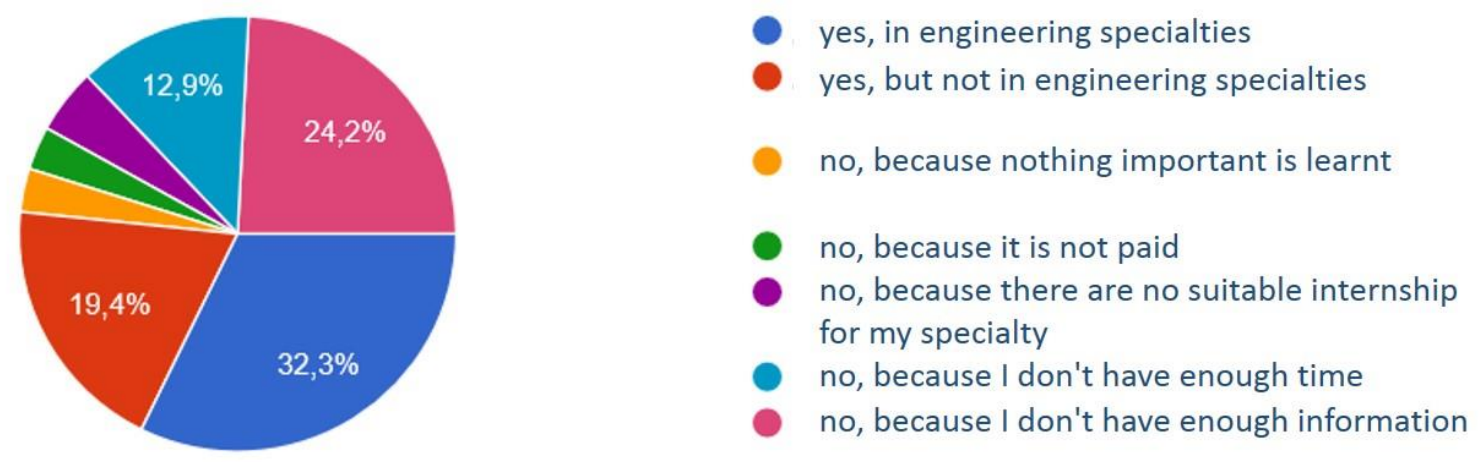

Source: Authors' illustration

The results indicate that only about $30 \%$ of the students and about $42 \%$ of the lecturers consider that the level of practical training is good enough to start work. The values of question № 17, presented in Figure 3, show that slightly more than half of the students (about $51 \%$ ) have been on internship, $32 \%$ of them in engineering and $19 \%$ in other specialties. The remaining $49 \%$ of the students say they did not have a professional internship for a variety of reasons, most notably for the lack of information on internships (about 24\%) and the lack of time for one (about 13\%). Both surveyed categories have the same opinion (44\% of the students and $42 \%$ of the lecturers) that the received education will help to find a job more easily. An analysis of the results on these questions shows that it is necessary to increase the time for professional practice and hence the confidence of the learners on the basis of the experience gained. It is advisable for the internship to be coordinated by the management of the educational institutions and carried out in the private sector. This will also improve the relationship between users and training institutions.

Question № 18 of the students' questionnaire is the same as question № 13 of the lecturers' questionnaire and is worded as follows: "To what extent do you think that motivation for training depends on the personal pursuit of self-improvement?"

Figure 4

Answer to Question № 18 (Students)

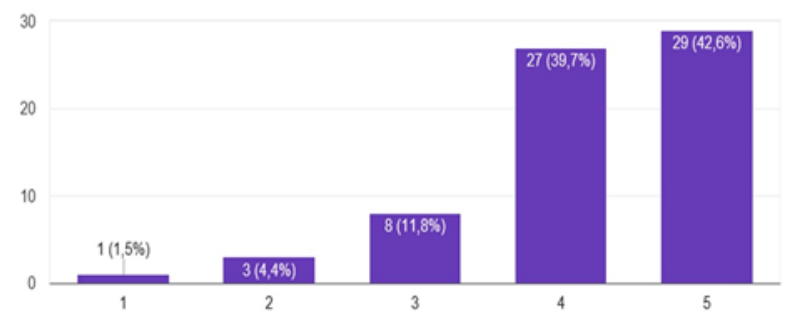

Source: Authors' illustration 
Figure 5

Answer to Question № 13 (Lectures)

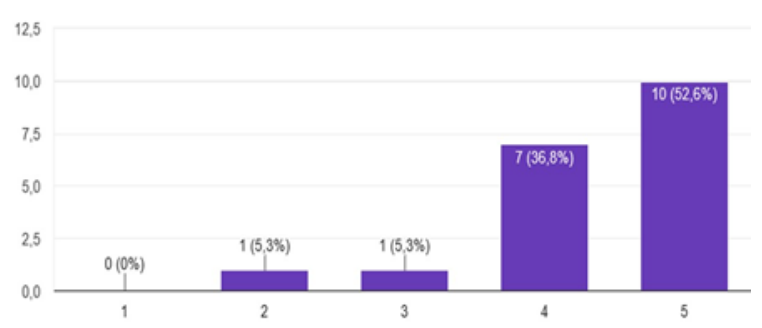

Source: Authors' illustration

The results of question № 18 are shown in Figure 4, and those of question № 13 - in Figure 5. They lead to the conclusion that the students and the teachers are convinced that there is a direct correlation between the pursuit of self-improvement and the motivation for training. That is, the greater the aspiration, the higher the motivation.

Questions № 19,21 and 22 of the students' questionnaire and questions № 14 and 16 of the lecturers' questionnaire reflect the opinion of the respondents about the satisfaction of what they learnt and of the choice of specialty. The results show that both categories believe that students are not sufficiently satisfied with what they have learnt in their specialty, but that over $50 \%$ of the students are satisfied for their choice of specialty. The students' answer to question № 22 is encouraging for the future of engineering specialties. More than $53 \%$ of them have stated that they would certainly choose engineering training again despite the difficulties in the learning process.

\section{Discussion}

From the study of motivation for training in engineering specialties and the analysis of the results obtained, the following conclusions could be made:

The choice of an engineering specialty is personal to the majority of students (over 75\%). The leading factor in this choice is the realisation on the labour market, followed by better opportunities for further training. They are part of the selfrealisation and growth of the personality and are classified as the highest needs in Maslow's hierarchy and the internal factors according to Herzberg. This is supported by the explicit opinion of both students and lecturers who believe that there is a direct relationship between the pursuit of self-improvement and the motivation for training. The secondary factors, such as the remuneration and location of future occupation, which are part of the Herzberg's external factors, also influence the choice of specialty.

At the beginning of their training students are highly motivated, and in the course of the training the level of motivation decreases. This is probably due to the difficulties and challenges they face. The lecturers' opinion differs as they think that students' motivation is low and that the students do not put enough effort into learning the material.

The analysis of the results on the question related to the factors influencing motivation in the course of training shows that what is paramount for both students and lecturers is the way of teaching, the practical direction of training and the content of curricula and syllabi. This leads to the conclusion that for both categories surveyed the most important is the optimal learning of the educational material, 
which will lead to progress, gaining experience and improvement, which again correspond to the highest levels of the internal factors under Herzberg and Maslow.

All categories surveyed are of the opinion that maintaining feedback between students and lecturers in the training process is mandatory in order to assist both parties, to identify problems in due time and take timely measures to solve them.

The results from other questions in the survey indicate that it is necessary to increase students' professional practice, which is appropriate to be coordinated by the management of the educational institutions and conducted in the private sector. This will lead to an improvement in the relationship between the users of the staff and the educational institutions.

Asked about their satisfaction, the students say that what they learnt in their specialty training is not enough, but it is a good starting point. For more than $50 \%$ of them, the choice of an engineering specialty brings satisfaction, with over $53 \%$ declaring that they would make it again. Hence comes the conclusion that, despite the difficulties in the training process, engineering specialties have a future that is proven by the demand in the labour market.

\section{Conclusion}

The analysis of the results on questions related to professional internships shows that only half of the students surveyed have been on one. This proves the need to improve the relationship between the educational institutions and the users in order to increase the practical training of engineering professionals.

The summarised results of the survey show that the motivation for training in engineering specialties has a complex structure. Initially, the choice of a specialty is dictated by both external factors and internal factors under Herzberg, but in the course of training, internal factors fully fill the motivational training structure, which leads to scientific advancement, progress in learning and personality development.

\section{References}

1. Burov, S., Pehlivanova, P. (1995), Rechnik na chuzhdite dumi v balgarski, Elpis, Veliko Tarnovo.

2. Ivanov, I. (2005), "Motivatsia v organizatsiyata" (Motivation and organisation), Gradev, D., Organizatsionna psihologia, Faber, Veliko Tarnovo.

3. Pencheva, I. (2007), "Motivatsia v organizatsionnoto povedenie", Lukanov, K., Organizatsionno povedenie, Abagar, Veliko Tarnovo, pp. 21-37

4. Penchev, P., Pencheva, I. (2016), "Motivatsia" (Motivation), Lukanov, K., Osnovi na upravlenieto, Abagar, V. Tarnovo.

5. Mullins, L. (2013), "Work Motivation and Job Satisfaction", "Management and Organisational Behaviour", London, pp. $252-269$.

6. Varadinova, J. (2015), "A Methodology for Conducting Surveys in Universities as Regards the Quality of Learning", XIII International Scientific Conference in Management and Engineering 2015, Sozopol, 2015. Technical University, Sofia, pp. 357-367.

7. Cherkezova, D (2014), „Prestizhat na profesiyata "inzhener" se vazrazhda“ (Presenting the profession "engineer" is revived), available at: https://www.capital.bg/biznes/kompanii/2014/03/05/2255251_prestijut_na_profesiiata injener_se_vuzrajda/ (6 March 2018) 


\section{About the authors}

Grigor Grigorov, PhD is an Assistant Professor at the Department of Resource and Technology Management at the Land Forces Faculty, Vasil Levski National Military University in Veliko Tarnovo, where he also received his PhD in Security and Defence in the field of Civil Military Cooperation. He also holds a Master's Degree in Psychology and Sociology of Management and ICE - engineer. He has participated in many international scientific conferences with reports in the field of security and management. The author can be contacted at gbgrigorov@nvu.bg.

Ilyan Lilov, PhD is a Full Professor at the Department of Resource and Technology Management, Vasil Levski National Military University, Veliko Tarnovo, where he received his $\mathrm{PhD}$ in Automatic in the field of Electronic computing. He also holds a Bachelor's degree in Finance and a Master's Degree in ICE - engineer. He is a consultant for project BG05M2OP001-2.009-0001-C01 with Horizon 2020. He has participated in many international scientific conferences. The author can be contacted at inid@nvu.bg. 